\title{
A CONSTRUÇÃO DA PERSONAGEM PERDITA DURANGO COMO ELEMENTO ESTÉTICO DE RESISTÊNCIA
}

\author{
Suellen Monteiro Batista ${ }^{1}$ \\ Neuton Vieira Martins Filho
}

Resumo: O artigo parte da hipótese de que a personagem Perdita Durango é construída de modo peculiar, por conta do seu caráter marginal, que a transforma em uma personagem que resiste aos padrões aceitos socialmente, como condizentes com o papel do feminino. Para tal análise iremos nos basear, principalmente, nas formulações de Bosi (1996) acerca da resistência enquanto conceito que transita entre o ético e o estético; nas considerações de Canclini (2008), sobre as dinâmicas sociais contemporâneas; e nas formulações de Beauvoir (1970) a cerca do feminino e das teorias que o cercam.

Palavras-chave: Marginal, feminino, resistência.

Abstract: The present article starts with the hypothesis that the character Perdita Durango has been built in a peculiar way, because of her marginal feature, which turns her in a character who resists to the standards socially accepted as consistent with the female role. To this analysis we will be mainly based on formulations of Bosi (1996), about the resistance as a concept that moves between the ethical and the aesthetic; Canclini (2008), about contemporary social dynamics; and Beauvoir (1970), about the feminine and the theories surrounding it.

Keywords: Marginal, female, resistance.

\footnotetext{
${ }^{1}$ Mestranda em Letras - Estudos Literários na UFPA. E-mail: suellenb@ufpa.br.

${ }^{2}$ Mestrando em Letras - Estudos Literários na UFPA. E-mail: neuton.contatos@gmail.com.
} 


\section{INTRODUÇÃO}

A discussão sobre a categoria da resistência tem sido alvo de reflexões dos estudos literários nos últimos anos. Um dos teóricos que tem se debruçado sobre esta categoria é Alfredo Bosi (2002), ao bordar a resistência ligada à narrativa literária, afirma a existência de duas formas de realização da resistência: a primeira como tema e a segunda enquanto forma imanente da escrita. Neste estudo, tomaremos como base a segunda forma de realização desta categoria, pois iremos investigar de que forma ocorre a manifestação imanente da resistência na narrativa fílmica Perdita Durango. A análise deste trabalho centra-se na resistência enquanto elemento da construção estética da personagem Perdita Durango, tornando-a não uma representação da rotina social, e sim do seu avesso. Esta análise centra-se na tensão entre o eu e o mundo.

Perdita Durango é uma adaptação do romance $59^{\circ}$ and raining: the story of Perdita Durango, do escritor americano Barry Gifford, publicada em 1992. O romance, por sua vez, é baseado em fatos reais: trata-se da história de Sara Aldrete, assassina em série envolvida com um grupo denominado Los Narcosatanicos. Aldrete é retratada como Perdita Durango nas obras de Gifford.

O filme narra a história de Perdita Durango, mulher mexicana que vive na fronteira entre os Estados Unidos e o México, que se envolve amorosamente com Romeo Dolorosa, homem mexicano praticante da Santeria ${ }^{3}$, religião que, apesar de demonstrar crença $a^{4}$, usa como espetáculo para obtenção de dinheiro. O filme centra a narrativa na relação entre os personagens (Romeo e Perdita) e nos desdobramentos dessa relação na vida de ambos.

A relação entre Perdita Durango e Romeo Dolorosa inicia com um encontro casual em um bar do lado americano da fronteira Estados Unidos/México. Alguns acontecimentos vividos pelos personagens antes deste encontro são apresentados no decorrer do filme em flash-back, um exemplo, é o assalto cometido por Romeo a um banco americano.

Toda a narrativa é envolvida em uma atmosfera marginal que abarca desde o ambiente em que se passa a narração até os personagens que transitam neste meio. Na composição deste aspecto do filme nota-se a influência da estética $k_{i t s c h}{ }^{5}$, responsável, por exemplo, pela presença de símbolos religiosos na construção de objetos profanos, assim como de elementos eróticos com formatos sugestivos ou sadomasoquistas, presentes no filme.

A obra nos possibilita diversas abordagens, uma como a relação entre a religiosidade e a identidade cultural de um povo e a ligação entre erotismo e violência. Dessa forma, abordaremos neste trabalho questões relacionadas ao místico, à cultura e ao feminino, presentes na construção da personagem Perdita Durango.

\footnotetext{
${ }^{3}$ A Santeria é uma religião afro-caribenha com base em crenças e tradições iorubá, com alguns elementos da religião Católica Romana, ou seja, constitui uma prática sincrética que mistura elementos profanos e cristãos. Esta religião também é conhecida como La Regla Lucumi e do Estado de Osha.

${ }^{4}$ O personagem julga ser Santeria responsável por permitir-lhe atravessar a fronteira Estados Unidos/México, embora seja procurado pela polícia em razão das atividades ilegais que exerce, como roubos e tráfico de drogas.

${ }^{5}$ Para mais informações sobre esta estética, pode-se consultar BELTRÃO \& WAECHTER (2008). Neste artigo os autores traçam um histórico da estética, assim como apontam os principais aspectos de sua composição, a partir de filmes de Almodóvar.
} 


\section{ACERCA DA RESISTÊNCIA E DE SUAS REALIZAÇÕES}

Como dito anteriormente, Bosi (2002) aponta a existência de dois modos de realização da ideia de resistência (enquanto tema e enquanto processo inerente à escrita). Convém salientar que, em ambas, subjaz a noção da realização da resistência a partir da representação de valores. São eles os responsáveis pela transição do conceito da esfera ética para esfera estética. Pois, "valores e antivalores não existem em abstrato, isto é, absolutamente. Tem todos, para cada um de nós, e de modo intenso para o artista uma fisionomia" (Bosi, 2002, p.120).

O modo intenso da fisionomia dos valores, a que faz referência o excerto anterior, é fundamental para compreendermos as construções das personagens nas obras de ficção, uma vez que ele é o responsável pela representação dos valores nas obras por meio da criação dos personagens. São eles que darão corpo e voz aos valores e/ou antivalores. Essa construção múltipla (valores e antivalores) será retomada adiante, quando analisarmos a personagem Perdita.

Ao observar a resistência enquanto tema Bosi (1996), chama a atenção para a forma dessa abordagem e observa como o elemento da resistência é usado na composição de um personagem que transcende o fato histórico e configura um indivíduo que funda "uma palavra radicalmente antiburguesa, não conformista, revolucionária, voltada para a construção do novo Homem em uma perspectiva imanente. [...] são seres que recusam.” (BOSI, 1996, p. 129).

A partir da idéia dos seres que se constroem em uma perspectiva imanente, é que pensamos no místico como elemento da constituição da personagem principal.

\section{O MÍSTICO}

Para Antônio Azevedo (2002, p. 259), o místico é definido como uma "atitude espiritual, íntima e intuitiva, que procura alcançar forças e entes sobrenaturais através da meditação, da prece, da contemplação e do êxtase".

Com isso podemos afirmar que o conceito de místico nos ajuda a compreender como a personagem Perdita foi construída no decorrer da narrativa, pois em suas ações observamos as manifestações do místico. Para elucidar esta idéia citamos a primeira cena do filme: Perdita sonha que um jaguar descobre seu corpo deixando-o nu, podemos considerar que a personagem estaria se encontrando com a entidade Jaguar. Entendemos que o sonho representa a divindade, revelando à protagonista quem ela realmente é. Em um sentido espiritual, o sonho explicaria os acontecimentos que sucedem: Perdita encontra Dolorosa e este lhe dá um direcionamento, um preenchimento, uma nova perspectiva à vida.

Devemos considerar a força da figura do Jaguar, como divindade presente no panteão das religiões dos povos indígenas de toda a América Latina. Lévi-Strauss (1991, p. 91-98) em sua obra Mitologia, apresenta seis versões de mitos que explicam a obtenção do fogo pelos homens. Em todas as versões - originária de tribos diferentes - o Jaguar é o detentor do fogo; caracterizando assim uma figura equivalente ao deus Zeus na Grécia antiga. Portanto, Perdita estaria tendo uma revelação mística, para Joistein Gaarder (2005, p. 37): 
A experiência mística pode ser caracterizada, resumidamente, como uma sensação direta de ser um só com Deus ou com o espírito do universo. [...] Em outras palavras: o místico não sente a existência desse abismo. Ele é "absorvido" em Deus, "se perde" em Deus, ou "desaparece" em Deus. Isso porque aquilo a que normalmente nos referimos como "eu" não é nosso eu real. O místico experimenta, pelo menos por instantes, a sensação de ser indivisível de um eu maior — não importa que ele dê a isso o nome de Deus, espírito universal, o eu, o vazio, o universo ou qualquer outra coisa. (Um místico indiano disse certa vez: "Quando eu existia, não existia Deus — agora Deus existe, e eu não existo mais". Ele "se perdeu" em Deus)

Neste viés, observamos que Bosi (1992) discute a influência da religião como elemento da formação de uma gênese social. Ainda segundo Bosi (1992, p. 15):

A possibilidade de enraizar no passado a experiência atual de um grupo se perfaz pelas mediações simbólicas? E o gesto, o canto, a dança, o rito, a oração, a fala que evoca, a fala que invoca? No mundo arcaico tudo isto é fundamentalmente religião, vínculo do presente com o outrora-tornado-agora, laço da comunidade com as forças que a criaram em outro tempo e que sustem a sua identidade.

A cultura latino-americana será marcante na constituição da personagem Perdita Durango um dos elementos que evidenciam a presença de resistência no filme. Um desses é o momento em que Perdita resiste a cultura norte-americana. Para ilustrar o que estamos analisando, citamos o momento em que seu parceiro Dolorosa cita um trecho do filme Batman de 1989, dirigido por Tim Burton, ao que ela responderá depreciativamente.

Diversas referências à cultura norte-americana estão presentes no filme, como, por exemplo, a trilha sonora, composta por músicas de Johnny Cash. Isto porque a opção do diretor Iglesia não é mostrar o México de forma usual ou realista, e sim representá-lo como local urbano, miscigenado, uma cultura híbrida, como nos fala Néstor Canclini (2008, p. 285):

Sem dúvida, a expansão urbana é uma das causas que intensificaram a hibridação cultural. O que significa para as culturas latino-americanas que países que no começo do século tinham aproximadamente $10 \%$ de sua população nas cidades, concentrem agora 60 ou $70 \%$ nas aglomerações urbanas? Passamos de sociedades dispersas em milhares de comunidades rurais com culturas tradicionais, locais e homogêneas, em algumas regiões com fortes raízes indígenas, com pouca comunicação com o resto de cada nação, a uma trama majoritariamente urbana, em que se dispõe de uma oferta simbólica heterogênea, renovada por uma constante interação do local com redes nacionais e transnacionais de comunicação.

A partir desta visão, podemos compreender como é formada a identidade daqueles que habitam em comunidades híbridas. Uma identidade advinda não apenas da tradição, mas pela dinâmica dos envolvimentos. Vejamos mais uma vez o que nos fala Néstor Canclini (2008, p. 190): 
Para radicalizar essa dessubstancialização do conceito de patrimônio nacional é necessário questionar essa hipótese central de tradicionalismo segundo a qual a identidade cultural se apóia em um patrimônio, constituído através de dois movimentos: a ocupação de um território e a formação de coleções. Ter uma identidade seria, antes de mais nada, ter um país, uma cidade, ou um bairro, um entidade onde tudo é compartilhado pelos que habitam esse lugar se torna idêntico ou intercambiável. Nestes territórios a identidade é posta em cena, celebrada em festas e dramatizada também nos rituais cotidianos.

Aqueles que não compartilham constantemente esse território, nem o habitam, nem têm, portanto os mesmo objetos e símbolos, os mesmos rituais e costumes, são os outros, os diferentes.

Como dito a cultura mexicana é elemento central na composição da personagem Perdita. É no México que Perdita joga as cinzas de sua irmã e onde a personagem se identifica enquanto sujeito.

A construção de Perdita faz referência ao ideal de nacionalidade mexicana. Sua aversão ao que vem ser norte-americano, o que Canclini (2008, p. 192) chama "os outros", fica evidente em momentos como na cena do flerte com um empresário norte-americano, e na escolha do casal de jovens para o sacrifício.

\section{O FEMININO}

Como antecipamos a personagem Perdita Durango é vítima de diversas formas de opressão. Há de se esperar isso considerando como a mulher, durante a história, tem sido alvo frequente de repressão e manipulação. Como pontuado por Sandra Azerêdo (2007, p. 24 e 25) a respeito do preconceito direcionado à mulher:

o tripé mãe/dona-de-casa, pai/provedor e a outra/puta talvez represente o protótipo no qual se assenta o preconceito contra a mulher. É claro que hoje ele está sendo profundamente abalado com a saída das mulheres para o mercado de trabalho, transformando a mãe/dona de casa, que antes era proibida de trabalhar, em provedora, o que lhe dá maior autonomia, mesmo com todos os conflitos relacionados ao trabalho doméstico, que continua a ser de sua responsabilidade exclusiva, já que a maioria dos homens se recusa a partilhar esse trabalho. O que é mais problemático, no entanto, é que, na imaginação de muitos homens, a saída de sua mulher para o trabalho - que já não pode ser proibida porque contribui de fato para o orçamento da casa, muitas vezes sendo a única fonte de renda da família - traz como conseqüência a busca de um sexo mais prazeroso, e a grande maioria das mulheres que buscam a delegacia de mulheres nos relata o enorme ciúme de seus companheiros, que as chamam de putas, mesmo quando elas não têm nenhuma relação fora de casa. 
No caso específico de Perdita, sua independência e sua capacidade de promover o sustento estão ligadas sempre a uma atividade marginalizada ou ilegal, como, por exemplo, a prostituição.

De fato, o sexo será marca de sua autonomia. Nota-se no decorrer da narrativa que Perdita não apresenta nenhum traço da repressão sexual comumente direcionada à mulher, como pontuado por Azerêdo (2007) na citação anterior, ao contrário, a personagem promove jogos sexuais no decorrer da trama, de forma desinibida e espontânea. Já nesse ponto, vemos como ela vai de encontro ao modelo de mulher imposto, comumente, pela sociedade.

Perdita pode ser tomada, em parte, como ícone de um feminino não condizente com o que Simone de Beauvoir (1970, p. 94) aponta como sendo o papel desempenhado pela mulher. O lugar de submissão teria sido dado às mulheres desde as sociedades totêmicas, e esta situação perduraria até a modernidade:

a mulher perpetua-lhes a existência carnal, mas seu papel é unicamente nutriente, não criador; em nenhum domínio ela cria: mantém a vida da tribo dando-lhe filhos e pão, nada mais; permanece votada à imanência; encarna somente o aspecto estático da sociedade, fechado sobre si.

Como Beauvoir faz esse levantamento a fim de criticar e denunciar esta cultura repressora, podemos afirmar que Perdita exemplifica o desfrutando da liberdade existencial proposta pela autora. Um exemplo deste aspecto é a fala da personagem, que pode ser tomada como um elemento revelador da quebra com o mito. Por meio dos diálogos que ela realiza percebe-se um posicionamento agressivo, que transcende um dizer e torna-se um colocar-se enquanto sujeito detentor de opinião e capaz de lidar de modo ativo em situações nas quais se esperava uma passividade feminina.

A fala assume um papel central na análise da resistência que propomos, que evidenciam nos momentos de flerte presentes no filme, por exemplo, quando abordada por Manny Flynn, vendedor de softwares, que se aproxima de Perdita e se coloca como detentor de um elevado status social, a personagem confronta-o ao mostrar-se conhecedora das intenções do homem que a aborda e, principalmente, ao colocar o sexo e, consequentemente, seu corpo como objeto para obtenção de dinheiro. A maneira como essa tomada de posição dá-se leva-nos a refletir sobre a fala enquanto uma possibilidade de realização da violência.

O falar está além de um dizer, é um colocar-se enquanto sujeito. Em Perdita Durango ela irá corresponder, sobretudo, a construção de uma identidade e a forma agressiva com que se manifesta, pode ser vista como um modo encontrado pela personagem para resistir a uma estrutura social que vê a mulher como um indivíduo oprimido e marginalizado. Ao tomar a palavra Perdita assume a voz, que no caso de uma sociedade patriarcal é monopolizada pelo homem, ocorrendo uma inversão de papéis: de oprimida passa a opressora.

Utilizando-se de elementos éticos, a obra expressa um efeito estético descrito por Jean -Paul Sartre (2004, p. 55 e 56) ao falar sobre o que é a literatura e sua importância ao homem:

Não existe liberdade dada; é preciso conquistar-se às paixões, à raça, à classe, à nação, e conquistar junto consigo os outros homens. Mas o que conta, neste caso, 
é a figura singular do obstáculo a vencer, da resistência a superar; é ela que dá, em cada circunstância, sua feição à liberdade.

O que Perdita busca é a sua identidade, reafirmá-la, reconstruí-la. A violência é uma forma de luta, pois para resistir, importa atacar, agredir, sabotar, física ou moralmente o opressor, seja o ato direcionado a todo sistema, seja a seus representantes.

Percebe-se esta troca de papéis sociais estereotipados, também, quando observamos a relação entre os personagens Estelle e Duane, jovens de classe média que mantém um relacionamento amoroso e que são sequestrados por Perdita e Romeo para serem sacrificados em um ritual da Santeria. Nota-se, no casal, que Estelle assume em diversas passagens do filme uma atitude ativa, que se convencionou associar ao masculino. Ela incita Duane a fugir quando são mantidos reféns por Perdita e Romeo e, em uma das passagens mais emblemáticas dessa inversão, ela realiza o papel do masculino na relação sexual, responsável por seduzir e convencer o outro de manter relações. Restando a Duane o papel do feminino, daquele que é conduzido, que é pudico e sente vergonha e/ou tem receio de ser visto mantendo relações sexuais.

A personagem Perdita é exemplar, também, para compreendermos o papel da mulher desvinculado do "Eterno Feminino único e cristalizado" (Beauvoir, 1970, p. 299), pois apresenta as marcas da força e do posicionamento masculino por meio de suas ações e falas e ao mesmo tempo revela, por meio de sonhos recorrentes com a morte da irmã e a mudança de comportamento em favor de Romeo ${ }^{6}$, a presença de um eu fragilizado e vitimizado, marcado pela culpa e pela violência. Essa construção da personagem demonstra a pluralidade de arquétipos que compõe o que vem a ser a mulher.

O filme Perdita Durango, possibilita a reflexão sobre a constituição híbrida da mulher, enquanto indivíduo capaz de transitar entre os papéis do masculino e do feminino. Compreender a personagem Perdita é compreender o modo como ela se constitui enquanto indivíduo; é percebê-la enquanto mulher inserida em um contexto social, que a vê como indivíduo oprimido, porém, que resiste a ele, seja pela fala ou pelas ações.

\section{CONCLUSÃO}

Entendemos o filme Perdita Durango como uma narrativa de resistência. Não por conta de um engajamento ideológico, mas em razão da resistência dos personagens a estruturas e modelos de comportamento social.

As personagens Perdita Durango e Romeo Dolorosa encontram na marginalidade e em atividades criminosas, a possibilidade de uma existência livre. A categoria resistência pode ser percebida a partir das ações empreendidas pelos personagens centrais do filme: Perdita Durango e Romeo Dolorosa. Ambos resistem ao sistema burlando e/ou infringindo suas regras. As personagens irão sempre de encontro a seus opostos, a nação, a classe, ao sexo.

\footnotetext{
${ }^{6}$ Tal mudança de comportamento é demonstrada na última cena do filme, na qual Perdita vaga, desorientada, por Las Vegas após ver Romeo ser assassinado. Esta atitude demonstra a fragilidade e a importância da relação com Romeo para a personagem.
} 
O elemento central de toda a análise da resistência realizada neste estudo encontrase na personagem Perdita Durando. Em sua natureza, Perdita, apresenta elementos alvos de preconceito e marginalização, haja vista ser mulher, mexicana, pobre e mestiça. Estes elementos também estarão presentes na construção do personagem Romeo, que rouba e se envolve com o tráfico de fetos, atitudes que evidenciam um ir de encontro ao que está estabelecido socialmente como correto. Tais atitudes trazem a personagem marcas de um não pertencer ao meio ao qual está inserido, o que irá aproximá-lo da personagem Perdita. $\mathrm{Na}$ relação estabelecida entre estes, nota-se que Perdita cede à figura masculina de Romeo e adere ao papel tradicional da mulher como outro, conforme aponta Beauvoir (1970, p. 15):

O homem que constitui a mulher como um Outro encontrará, nela, profundas cumplicidades. Assim, a mulher não se reivindica como sujeito, porque não possui os meios concretos para tanto, porque sente o laço necessário que a prende ao homem sem reclamar a reciprocidade dele, e porque, muitas vezes, se compraz no seu papel de Outro.

Fica evidenciado que Perdita é vista como o outro, pois com a morte de Dolorosa, o agente federal que os perseguia não faz questão de prendê-la, apesar de ter a oportunidade. Embora, considerando todo o desenrolar da trama, tenhamos constatado que Perdita Durango é mais que o outro de Romeo, ela é essencial para o sucesso de seus planos, ela completa sua existência e é completada por este, estando, sempre, em pé de igualdade, não há subjugação entre eles, apenas um compartilhar de liberdade.

\section{REFERÊNCIAS}

ABRAHAM, Moles. O kitsch. São Paulo: Perspectiva, 1994.

AZERÊDO, Antônio Carlos. Dicionário histórico de religiões. Rio de Janeiro: Nova Fronteira, 2002.

AZERÊRO, Sandra. O preconceito contra a "mulher": diferenças, poemas e corpos. São Paulo: Cortez, 2007.

BEAUVOIR, Simone. O segundo sexo I: fatos e mitos. 4. ed. São Paulo: Difusão Europeia do Livro, 1970.

BOSI, Alfredo. Dialética da colonização. 3. ed. São Paulo: Companhia das Letras, 1992.

BOSI, Alfredo. Literatura de resistência. São Paulo: Companhia das Letras, 2002.

CANCLINI, Nestor Garcia. Culturas híbridas. São Paulo: Edusp, 2008.

GAARDER, Jostein; HELLERN, Victor; HENRY, Notaker. O livro das religiões. São Paulo: Companhia das Letras, 2005. 
LÉVI-STRAUSS, C. “O cru e o cozido". In: Mitológicas. Tradução de Beatriz Perrone-Moisés.

São Paulo: Cosac Naify. 1991. Vol. 1.

SARTRE, Jan-Paul. Que é a Literatura? 3. ed. São Paulo: Ática, 2004.

\section{FILMOGRAFIA}

PERDITA Durango. Direção de Alex de La Iglesia Produção de André Vicente Gómez. México/EUA/ Espanha: Lolafilms e Mirador S.A de C.V, 1997. (126 min), Cor. 